\title{
Retrograde cerebral venous air embolism following difficult intubation
}

\author{
Pierre Huette, MD (1) - Camille Daumin, MD - Osama Abou Arab, MD • Yazine Mahjoub, MD, PhD
}

Received: 28 November 2018/Revised: 4 December 2018/Accepted: 4 December 2018/Published online: 12 December 2018

(c) Canadian Anesthesiologists' Society 2019

A 53-yr-old male undergoing elective video-assisted thoracoscopic pulmonary resection was found to have a grade-III view on direct laryngoscopy. This required the use of a bougie (15 Fr Eschmann introducer; Vygon ${ }^{\circledR}$, Ecouen, France) on the second attempt at intubation, after which subcutaneous emphysema was noted on the neck. As the patient was deeply anesthetized and paralyzed by cisatracurium, a third attempt successfully used flexible bronchoscopy and a $7.0 \mathrm{~mm}$ armored endotracheal tube (Covidien ${ }^{\circledR}, \quad$ Mansfield, Ireland) for nasotracheal intubation. Tracheal suctioning revealed some blood attributed to the difficult airway management. Surgery proceeded uneventfully and required neither lung isolation or carbon dioxide insufflation.

After completing the operation, the patient was admitted to the intensive care unit for postoperative sedation and mechanical ventilation, where the initial clinical examination did not reveal any specific issues. Nevertheless, ecchymosis of the right side of the face and the right upper limb combined with a bilateral mydriasis developed within the first few postoperative hours. A cerebral computed tomography scan (Figure) showed unilateral intracerebral venous air with extensive bilateral edema, and a midline shift of the right cerebral hemisphere. Vascular ultrasound of the right jugular and brachiocephalic vein using a 12-3 Mhz straight linear array probe (Philips CX50; Guilford, England) showed significant air passage into the right brachiocephalic and internal jugular veins during the inspiratory cycle. The patient died approximately $24 \mathrm{hr}$ later and a post-mortem examination revealed a fistula between the brachiocephalic vein and the right side of the trachea at the level of the third and fourth tracheal rings.

P. Huette, MD $(\varangle) \cdot$ C. Daumin, MD · O. Abou Arab, MD . Y. Mahjoub, MD, PhD

Department of Anesthesiology and Critical Care Medicine, Amiens University Hospital, Amiens, France

e-mail: huette.pierre@gmail.com

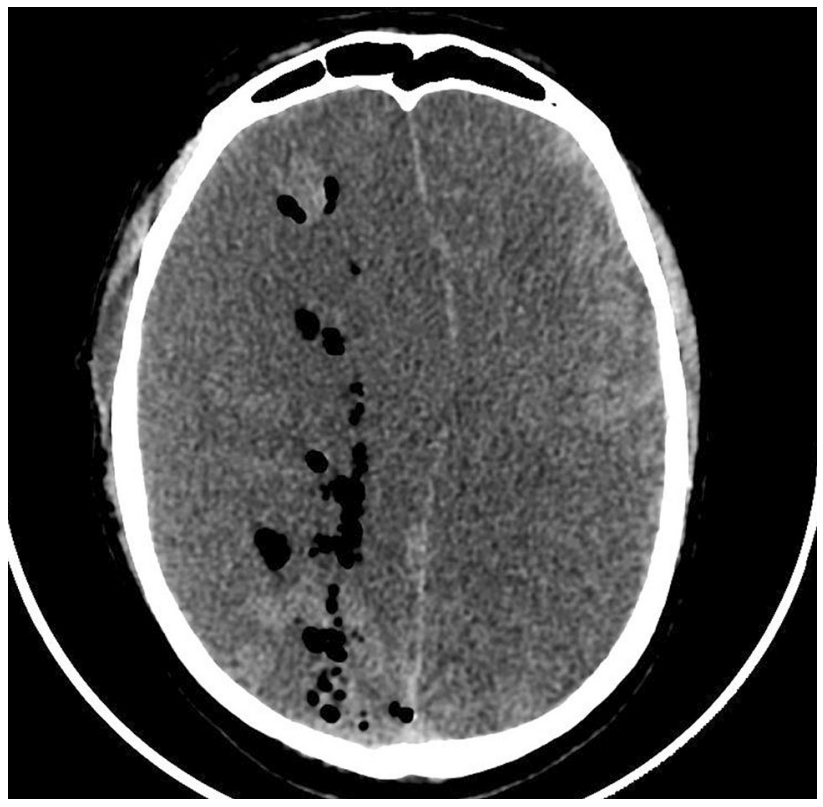

Figure Cerebral computed tomography scan in a patient following a bougie-related tracheal injury incurred during a difficult intubation attempt. Extensive intracerebral air, consistent with a retrograde cerebral venous air embolism, can be seen unilaterally in the right hemisphere along with diffuse cerebral edema and a midline shift

Retrograde cerebral venous air embolism has been previously reported in the setting of central venous cannulation. ${ }^{1}$ In addition to general supportive care related to its cerebral consequences, the use of Trendelenburg positioning and high concentrations of inspired oxygen (including hyperbaric oxygen) should also be instituted as soon as it is recognized. ${ }^{2}$

In summary, we report a unilateral retrograde cerebral venous air embolism, a previously unreported complication of bougie introducer use. ${ }^{3}$

\section{Conflicts of interest None declared.}

Informed consent Consent was obtained from the family for publication of this report. 
Editorial responsibility This submission was handled by Dr. Hilary P. Grocott, Editor-in-Chief, Canadian Journal of Anesthesia.

\section{References}

1. Jalota L, Aryal MR, Jain S. Iatrogenic venous air embolism from central femoral vein catheterisation. BMJ Case Rep 2013; DOI: https://doi.org/10.1136/bcr-2013-008965.
2. Schlimp CJ, Bothma PA, Brodbeck AE. Cerebral venous air embolism: what is it and do we know how to deal with it properly? JAMA Neurol 2014; 71: 243.

3. Arndt GA, Cambray AJ, Tomasson J. Intubation bougie dissection of tracheal mucosa and intratracheal airway obstruction. Anesth Analg 2008; 107: 603-4. 